Research Article

\title{
Bacterial infections in cirrhosis - does standard empirical therapy need a rethink?
}

\author{
Shiran Shetty ${ }^{1,2} *$, Venkatakrishnan Leelakrishnan ${ }^{2}$, Krishnaveni Janarthanan ${ }^{2}$
}

\author{
${ }^{1}$ Department of \\ Gastroenterology and \\ Hepatology, Kasturba Medical \\ College, Manipal, University, \\ Manipal, India \\ ${ }^{2}$ PSG Institute of Medical \\ Sciences and Research, \\ Coimbatore, Tamilnadu, India
}

Received: 06 June 2016

Accepted: 04 July 2016

*Correspondence to:

Dr. Shiran Shetty,

Email: drshiran@gmail.com

Copyright: (C) the author(s), publisher and licensee Medip Academy. This is an openaccess article distributed under the terms of the Creative Commons Attribution NonCommercial License, which permits unrestricted noncommercial use, distribution, and reproduction in any medium, provided the original work is properly cited.

\begin{abstract}
Background: Patients with cirrhosis not only have a higher incidence and a greater severity of infections but infections increase the mortality and morbidity in cirrhosis. Third-generation cephalosporins and quinolones are currently the most commonly recommended first-line empirical therapy in most infections. This study was conducted to study the bacterial etiology, susceptibility of these organisms to these commonly used antibiotics.

Methods: All patients of cirrhosis of liver admitted to a tertiary care centre underwent cultures from blood, urine and ascitic fluid and the incidence of infection was calculated. Sensitivity pattern of organisms to third generation cephalosporins and quinolones were studied.

Results: A total of 150 patients were included in the study and 58 (37.8\%) of them had one or more infections. Spontaneous bacterial peritonitis was the most common infection noted and gram-negative bacilli (E. coli) were the commonest organisms isolated. The overall response rate to quinolones and third generation cephalosporin's was only $47 \%$.

Conclusions: Increasing use of antibiotics in empirical role has increased resistance to commonly used antibiotics. Empirical therapy should be decided based upon local epidemiological patterns and the same cannot be generalized.
\end{abstract}

Keywords: Cirrhosis, Infection, Empirical therapy, Antibiotic resistance

\section{INTRODUCTION}

The liver being an organ with diverse functions plays a significant role in immune regulation. Anatomically it is the gatekeeper of the intestines. Receiving all the portal blood flow it is exposed to various infective and toxic challenges and responds to the same. Physiologically it plays a significant role in both innate as well as adaptive immunity. While liver contributes to innate Immunity through phagocytosis of pathogens by kupffer cells, synthesis of acute phase proteins like compliments, haptoglobulin etc., it also contributes to adaptive immunity. ${ }^{1}$ No doubt liver dysfunction associated with cirrhosis of liver increases susceptibility to infection. Other factors such as alcoholism, malnutrition, gastrointestinal haemorrhage, invasive diagnostic/therapeutic procedures and altered permeability of intestinal mucosa, predispose to bacterial infections. ${ }^{2,3}$ This study was aimed at identifying pattern of infections, determining the causative agent and assessing their sensitivity patterns in cirrhotic patients.

\section{METHODS}

This was a retrospective study carried out at tertiary care medical college hospital PSG Institute of Medical Sciences and Research, Coimbatore, Tamilnadu, India from January 2010 - December 2011. Hospitalized patients with cirrhosis of liver were included in the study. Patients meeting the inclusion criteria who underwent hematological, biochemical tests, ascites and cultures within 24 hours after admission were included. Those 
patients with hepatocellular carcinoma, HIV infection, diabetes and history of antibiotic use within the past one week, recent hospitalization were excluded. The data was collected pattern of infection and sensitivity to the commonly used antibiotics, i.e. III generation cephalosporins and fluroquinolones was then assessed.

Diagnosis of cirrhosis was made based on medical history, clinical signs, laboratory, sonographic, endoscopic finding and histology whenever available. Diagnosis of spontaneous bacterial peritonitis (SBP) was based on presence of ascitic fluid PMNL count $>250$ cells with positive ascetic fluid cultures in the absence of clinical signs and laboratory evidence of secondary peritonitis.

\section{Diagnostic tests}

Ascitic fluid paracentesis was carried out at the earliest in all patients with decompensated cirrhosis and analysed for total and differential counts. In addition about $10 \mathrm{ml}$ of fluid was aseptically inoculated into BacT/ALERT semi-automated blood culture bottles. Blood, sputum and urine cultures were collected as clinically indicated. Blood was also collected in BacT/ALERT blood culture bottles. BacT samples which marked positive were sub cultured on $5 \%$ sheep blood agar and MacConkey agar plates. Gram staining was also performed. Standard biochemical tests were used to identify the causative specimen. Mid-stream urine samples were collected with adequate aseptic precautions and transported in a sterile container. Samples were streaked on 5\% sheep blood agar and MacConkey agar plates by semi quantitative loop method. After identification of organisms disc diffusion was used for susceptibility testing.

\section{RESULTS}

150 patients met inclusion criteria and were included in the study. Of them $58(38.7 \%)$ were found to have culture positive infection. The most common etiology for the parenchymal liver disease was found to be ethanol 93/150 (62\%). Age, gender and child pugh score of patients are summarized in Table 1.

Table 1: Demographic data of patients.

\begin{tabular}{|ll|}
\hline Mean age of patients & $\mathbf{5 7 . 6 \pm 6 . 2}$ \\
\hline Gender & \\
\hline Males & $86(57 \%)$ \\
\hline Females & $64(43 \%)$ \\
\hline Child Pugh Score & \\
\hline B & $60(40 \%)$ \\
\hline C & $90(60 \%)$ \\
\hline
\end{tabular}

While the presenting complaints varied from jaundice to hepatic encephalopathy. Escherichia coli were the most commonly cultured organism and showed $56 \%$ resistant strains. Figure 1 depicts the organisms' isolated and antibiotic sensitivity pattern.

Table 2: Summarizes findings of various studies.

\begin{tabular}{|c|c|c|c|c|}
\hline & Prior to 1995 -Eight studies ${ }^{9-16}$ & 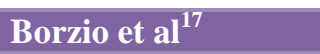 & Fernandez et al $^{16}$ & Present study \\
\hline Year of study & Prior to 1995 & 1995-1996 & $1998-2000$ & 2010-2011 \\
\hline No of patients & 658 & 361 & 1567 & 150 \\
\hline Incidence & $20-60 \%$ & $34 \%$ & $32 \%$ & $38.7 \%$ \\
\hline $\begin{array}{l}\text { Most common site } \\
\text { of infection }\end{array}$ & Urinary tract infection & $\begin{array}{l}\text { Urinary tract } \\
\text { infection }\end{array}$ & SBP & SBP \\
\hline $\begin{array}{l}\text { Most common } \\
\text { Organism isolated }\end{array}$ & Gram negative bacilli & Gram negative bacilli & $\begin{array}{l}\text { Gram-positive } \\
\text { cocci }\end{array}$ & $\begin{array}{l}\text { Gram negative } \\
\text { bacilli }\end{array}$ \\
\hline
\end{tabular}

\section{DISCUSSION}

Infections are rightly a menace in the management of cirrhosis due to its associated morbidity and its role as a trigger to mortality. Patients with cirrhosis have a higher incidence and a greater severity of infections compared to those without cirrhosis. ${ }^{4}$ Some studies have attributed bacterial infections to be the most common acute triggering event in ACLF. ${ }^{5}$ Such is the devastation of infection that lately more emphasis is laid on prevention of infections rather than treatment. Quinolones (ciprofloxacin and norfloxacin) and third generation cephalosporins (ceftriaxone, cefotaxime) are now recommended prophylactically in those at high risk for infections, like patients with upper gastrointestinal bleed, history of SBP, low ascetic fluid protein levels. ${ }^{6}$ This approach has been shown to decrease infection rates and also have a positive effect on overall mortality. ${ }^{6}$ However the same drugs also recommended as first line empirical therapy in commonly encountered infection. While third generation cephalosporins (cefotaxime/ceftriaxone) are advised for SBP, UTI. ${ }^{7,8}$ Quinolones are used as first line drugs in urinary tract infections and pneumonia. Various factors now pose a challenge to this recommended empirical therapy. 


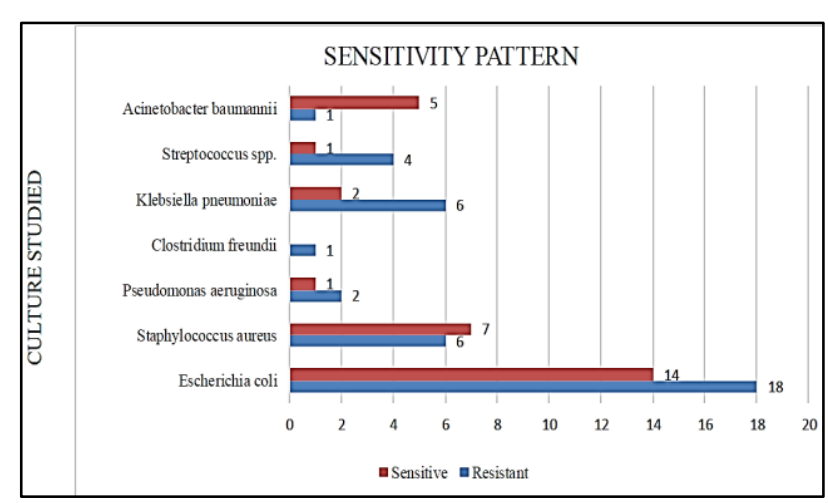

Figure 1: Chart depicting commonly isolated organism and sensitivity pattern to third generation cephalosporins and quinolones.

A summary of eight studies done before 1995 involving 658 patients showed that majority of infections were community acquired and caused by gram negative bacilli. ${ }^{9-16}$ Borzio et al showed that though vast infections were still caused by gram-negative bacilli but nearly $41 \%$ of infections were nosocomial. ${ }^{17}$ Studies done in the last decade however have shown predominance of grampositive cocci ( $51 \%$ of total infection) showing changing bacterial epidemiology. The author has postulated that widespread use of norfloxacin for SBP prophylaxis and high degree of instrumentation are responsible for this shift. ${ }^{16}$ Table 2 summarizes findings of various studies discussed above. Unlike the recent study gram negative bacilli formed the bulk of infections in our series and $\mathrm{E}$ coli was the commonest organism isolated (42\%).

Currently there is increasing burden of health care associated, nosocomial, and community acquired infections. Recent epidemiological studies done in cirrhosis have shown an increase in health care acquired (HCA) and hospital acquired (HA) infection. Health care associated infections accounted for $32-44 \%$ and hospital acquired infection made up $36-40 \%$ of total infections in two different studies. ${ }^{18,19}$ While $64 \%$ of HCA and HA strains were resistant in the first study, second study showed multidrug resistant strains in $4 \%, 14 \%$, and $35 \%$ of CA, HCA and HA infections. ${ }^{18}$ The efficacy of currently recommended empirical antibiotic therapy (ceftriaxone, quinolones and macrolides) was low in HCA and HA infections episodes ( $73 \%$ and $40 \%$ respectively) when compared to community acquired infections $(83 \%) .{ }^{19}$ In our study $53 \%$ of the isolated organisms were resistant to recommended empirical therapy.

To summarize unlike recent studies done in western countries which show a recent predominance of infections with gram positive bacteria out study showed the bulk of infections being caused by gram negative infections. ${ }^{16}$ Greater than $50 \%$ of infections seen were resistant to routinely used antibiotics. The finding of a below 50\% response to routine antibiotics in this study emphasizes the fact that bacterial epidemiology and sensitivity patterns vary among different countries and empirical therapy cannot be generalized. Individualization of treatment policies considering local sensitivity pattern is thus necessary for better outcomes.

\section{CONCLUSION}

Cirrhosis of liver is associated with a high incidence of infections and is a leading cause of significant morbidity and mortality. With resistance to commonly used antibiotics are found in nearly $50 \%$ of organisms isolated, empirical therapy needs to account for local epidemiology and sensitivity pattern and thus can't be generalized.

Funding: No funding sources

Conflict of interest: None declared

Ethical approval: The study was approved by the Institutional Ethics Committee

\section{REFERENCES}

1. Racanelli V, Rehermann B. The liver as an immunological organ. Hepatology. 2006;43(2 Suppl 1):S54-62.

2. Roselle GA, Mendenhall CL. Alteration of in vitro human lymphocyte functions by ethanol, acetaldehyde and acetate. J Clin Lab Immunol. 1982;9(1):33-7.

3. Deschênes M, Villeneuve JP. Risk factors for the development of bacterial infections in hospitalized patients with cirrhosis. Am J Gastroenterol. 1999;94(8):2193-7.

4. Jalan R, Fernandez J, Wiest R, Schnabl B, Moreau R, Angeli $\mathrm{P}$, et al. Bacterial infections in cirrhosis: A position statement based on the EASL Special Conference 2013. J Hepatol. 2014;60(6):1310-24.

5. Moreau R, Jalan R, Gines P, Pavesi M, Angeli P, Cordoba J, et al. Acute-on-chronic liver failure is a distinct syndrome that develops in patients with acute decompensation of cirrhosis. Gastroenterology. 2013;144(7):1426-37.

6. European association for the study of the liver. EASL clinical practice guidelines on the management of ascites, spontaneous bacterial peritonitis, and hepatorenal syndrome in cirrhosis. $\mathrm{J}$ Hepatol. 2010;53:397-417.

7. Runyon BA. Management of adult patients with ascites due to cirrhosis: an update. Hepatology. 2009;49(6):2087-107.

8. Wong F, Bernardi M, Balk R, Christman B, Moreau $\mathrm{R}$, Garcia-Tsao G, et al. Sepsis in cirrhosis: report on the $7^{\text {th }}$ meeting of the International Ascites Club. Gut. 2005;54(5):718-25.

9. Suárez C, Pajares JM. Epidemiology of infections in liver cirrhosis. Rev Clin Esp. 1981;160(5):299-303.

10. Rimola A, Bory F, Planas R, Xaubet A, Bruguera M RJ. Infecciones bacterianas agudas en la cirrosis hepática. Gastroenterol Hepatol. 1981;4:453-8.

11. Palazón JM, Garcia AGA. Infecciones hospitalarias en pacientes con cirrosis hepática. Gastroenterol Hepatol. 1984;7:120-2. 
12. Levi D, Terg R, Podesta A, Abecasis R, de Gle G RC. Infecciones bacterianas en el paciente cirrótico. Gastroenterol Hepatol. 1989;12:384-8.

13. Clemente G, Barajas JM, Serrano MI, Pérez de Ayala MV, Menchén P, Senent MC, et al. Infecciones bacterianas en la cirrosis hepática. Gastroenterol Hepatol. 1986;9:285-90.

14. Caly WR, Strauss E. A prospective study of bacterial infections in patients with cirrhosis. J Hepatol. 1993;18(3):353-8.

15. Andreu M, Barrufet $P$, Force L, Solá R, Verdaguer A, Panadés AAR. Fiebre en el enfermo con cirrosis hepática: estudio prospectivo durante 6 meses. Med Clin. 1985;84:433-6.

16. Fernández J, Navasa M, Gómez J, Colmenero J, Vila $\mathrm{J}$, Arroyo V, et al. Bacterial infections in cirrhosis: epidemiological changes with invasive procedures and norfloxacin prophylaxis. Hepatology. 2002;35(1):140-8.

17. Borzio M, Salerno F, Piantoni L, Cazzaniga M, Angeli P, Bissoli F, et al. Bacterial infection in patients with advanced cirrhosis: a multicentre prospective study. Dig Liver Dis. 2001;33(1):41-8.

18. Merli M, Lucidi C, Giannelli V, Giusto M, Riggio O, Falcone M, et al. Cirrhotic patients are at risk for health care-associated bacterial infections. Clin Gastroenterol Hepatol. 2010;8(11):979-85.

19. Fernández J, Acevedo J, Castro M, Garcia O, de Lope CR, Roca D, et al. Prevalence and risk factors of infections by multiresistant bacteria in cirrhosis: a prospective study. Hepatology. 2012;55(5):1551-61.

Cite this article as: Shetty S, Leelakrishnan V, Janarthanan K. Bacterial infections in cirrhosis does standard empirical therapy need a rethink? Int J Basic Clin Pharmacol 2016;5:1613-6. 